\title{
OPERATING SPECIFICATIONS OF CATALYTIC CLEANING OF GAS FROM BIOMASS GASIFICATION
}

\author{
Martin Liś̛**, Marek Baláš, Michal ŠpiláčeK, ZdeněK SkÁla \\ Dep. Power Engineering, Energy Institute, Faculty of Mechanical Eng., Brno University of Technology, \\ Technická 2896/2, Brno 616 69, Czech Republic \\ * corresponding author: lisy@fme.vutbr.cz
}

\begin{abstract}
The paper focuses on the theoretical description of the cleaning of syngas from biomass and waste gasification using catalytic methods, and on the verification of the theory through experiments. The main obstruction to using syngas from fluid gasification of organic matter is the presence of various high-boiling point hydrocarbons (i.e., tar) in the gas. The elimination of tar from the gas is a key factor in subsequent use of the gas in other technologies for cogeneration of electrical energy and heat. The application of a natural or artificial catalyst for catalytic destruction of tar is one of the methods of secondary elimination of tar from syngas. In our experiments, we used a natural catalyst (dolomite or calcium magnesium carbonate) from Horní Lánov with great mechanical and catalytic properties, suitable for our purposes. The advantages of natural catalysts in contrast to artificial catalysts include their availability, low purchase prices and higher resilience to the so-called catalyst poison. Natural calcium catalysts may also capture undesired compounds of sulphure and chlorine. Our paper presents a theoretical description and analysis of catalytic destruction of tar into combustible gas components, and of the impact of dolomite calcination on its efficiency. The efficiency of the technology is verified in laboratories. The facility used for verification was a $150 \mathrm{~kW}$ pilot gasification unit with a laboratory catalytic filter. The efficiency of tar elimination reached $99.5 \%$, the tar concentration complied with limits for use of the gas in combustion engines, and the tar content reached approximately $35 \mathrm{mg} / \mathrm{m}_{\mathrm{n}}^{3}$. The results of the measurements conducted in laboratories helped us design a pilot technology for catalytic gas cleaning.
\end{abstract}

KEYWORDS: biomass; gasification; gas cleaning; dolomite.

\section{INTRODUCTION}

Thermochemical gasification is a conversion of organic matter into gas with low lower heating value $\left(\mathrm{CO}, \mathrm{H}_{2}\right.$, $\mathrm{CH}_{4}, \mathrm{CO}_{2}, \mathrm{~N}_{2}$, and $\mathrm{H}_{2} \mathrm{O}$ ) and at high temperatures $\left(750-1000^{\circ} \mathrm{C}\right)$. The partial oxidation of gasified material (gasification using air, oxygen, steam) commonly supplies heat for endothermic reactions. The prevailing technology utilizes air. Thanks to this technology, there are no costs or hazards concerning oxygen production and utilization, as well as there are no costs and complexity regarding the reactors for gasification in steam and pyrolysis, which requires two reactors. The produced gas is suitable for the operation of boilers, engines and turbines; however, it is not suitable for transfer via gas lines, due to low energy density $\left(4-7 \mathrm{MJ} / \mathrm{m}_{\mathrm{n}}^{3}\right)$.

Gas comprises trace amounts of higher hydrocarbons such as ethane and ethene, small particles of charcoal and ashes, tar and other substances. Tar is a complex and heterogeneous mixture of hydrocarbons with a wide range of molar weights, yet there was no exact definition [1]. Therefore, several institutes cooperated to create a unified definition, the so-called Tar Protocol, which introduces the following delimitation: "Tar includes all organic materials which have a higher boiling point than benzene (i.e., $80.1^{\circ} \mathrm{C}$ )". In addition to that, the Tar Protocol presents a uniform methodology for sampling and analysis of tar, which will clearly help increase the comparability of particular published results.

Almost every gas produced from gasification of biomass contains at least a minimum amount of tar, and this creates serious problems for its subsequent use. Due to high concentrations of tar, several biomass gasification projects were discontinued. Successful elimination of tar from produced gas requires information about gas composition, physical-chemical properties, sampling conditions and a tar sample analysis.

\section{Gas CleAning Methods}

Tar production from wood gasification is much higher than tar production from coal and/or peat gasification, and it is composed of heavier and more stable aromatic substances [2, which means that the technologies developed for the elimination of tar from coal gasification may not be transferrable onto the elimination of tar from biomass gasification. Therefore, our research focuses on the elimination of tar from biomass gasification, i.e., on efficient elimination of tar. 
The methods leading to a decrease in tar concentrations in the produced gas may be classified according to various criteria. The fundamental classification distinguishes between primary and secondary measures for tar elimination. Current research suggests that the use of primary methods may decrease tar content; however, the methods are inefficient for complete tar elimination, at least for large-scale gasification systems [3] 5 .

\subsection{SECONDARY MEASURES}

Secondary measures focus on tar elimination in subsequent filtration routes. There are various methods for the elimination of tar from gas [6], and it is impossible to opt for the best method unanimously. Selecting a particular method for a particular process of tar elimination is always a result of optimization and compromise between several important factors such as efficiency, pressure drop, energy intensity, reliability, universality, investment and operating indicators, waste production, etc.

\subsection{USE OF CATALYSIS}

Since the mid-1980s, many research institutes have been interested in the use of catalysts for the modification of syngas, especially for tar elimination.

Requirements for catalyst properties [3]:

(1.) The catalyst must be highly efficient in tar elimination.

(2.) If syngas is to be produced, the catalyst must be able to reform methane.

(3.) The catalyst should produce $\mathrm{H}_{2}$ : $\mathrm{CO}$ in a suitable ratio.

(4.) The catalyst should be resistant to deactivation, fouling and fusing.

(5.) The catalyst should regenerate easily.

(6.) The catalyst must be sturdy and resistant to scratching.

(7.) The catalyst should be cheap.

Tar reduction on the surface of the catalyst occurs with steam or with $\mathrm{CO}_{2}$ :

$$
\begin{aligned}
& \mathrm{C}_{n} \mathrm{H}_{m}+n \mathrm{H}_{2} \mathrm{O} \longleftrightarrow \mathrm{CO}+\left(n+\frac{m}{2}\right) \mathrm{H}_{2}, \\
& \mathrm{C}_{n} \mathrm{H}_{m}+n \mathrm{CO}_{2} \longleftrightarrow 2 n \mathrm{CO}+\frac{m}{2} \mathrm{H}_{2} .
\end{aligned}
$$

In addition to dry and steam reforming, hydrogenation, hydrocracking, catalytic pyrolysis and polymerization also participate in tar elimination, under specific conditions [7]. All these reactions occur with catalysts. A detailed and accurate description of the reactions is not yet available. The reactions differ for individual tar components, and depend on the content of $\mathrm{H}_{2}, \mathrm{H}_{2} \mathrm{O}$ and $\mathrm{CO}_{2}$ in the gas, and on the temperature [7]. Studies conducted in laboratory conditions proved that reactions of dry reforming (2) prevail for temperatures exceeding $850^{\circ} \mathrm{C}$. This type of reaction requires high temperatures, but it is less energy intensive.

Natural materials, such as dolomites, zeolites and limestones, are commonly used for tar elimination. Various industrial metallic Ni, Mo, Co, Pt, Ru-based and other element catalysts are used as well.

Numerous factors influence the catalyst, and they may all worsen its catalyzing properties. Some of these factors work slowly, others may destroy the catalyst in a relatively short period of time [8]. The main causes of decline in catalyst functions include thermal instability of the catalyst, fouling, and catalyst poisoning.

\subsection{NATURAL CATALYSTS}

In contrast with industrial catalysts, natural catalysts do not eliminate tar as efficiently [3, 9. Other disadvantages include their high operating temperatures. The minimum operating temperature is around $800^{\circ} \mathrm{C}$ [3], and the optimum temperature is around $900^{\circ} \mathrm{C}$ and higher [5, 10].

Yet, natural catalysts have numerous advantages and may be adopted in tar elimination from syngas [3. 11]:

(1.) They are cheap and readily available.

(2.) They are not prone to catalyst poisoning and thermal instability, as opposed to metallic catalysts.

(3.) They easily regenerate when fouled.

(4.) They are relatively mechanically resistant.

Another non-disputable advantage of calcic catalysts is their ability to eliminate sulphure and chlorine compounds. On the other hand, these substances may be totally destructive for metallic catalysts.

Diverse types of natural materials, e.g., dolomite, olivine, limestone, zeolite, magnesite and others, were tested $\left[7+10\right.$. Dolomite $\left(\mathrm{CaMg}\left(\mathrm{CO}_{3}\right)_{2}\right)$ and olivine $\left(\mathrm{FeMg}\left(\mathrm{SiO}_{4}\right)_{2}\right)$ seem to be the most efficient. Limestone and magnesite may also work; however, they are not as active as dolomite [3].

Dolomite $\left(\mathrm{CaMg}\left(\mathrm{CO}_{3}\right)_{2}\right)$ is the most common and definitely most used natural material for catalytic elimination of tar 17. Its exact chemical composition varies depending on the site of extraction. In general, dolomite contains about $30 \mathrm{wt} \% \mathrm{CaO}, 21 \mathrm{wt} \% \mathrm{MgO}$, and $45 \mathrm{wt} \% \mathrm{CO}_{2}$ [3], as well as other mixtures, especially metal oxides (iron, aluminum), alkali metal oxides, silicon oxides, etc.

Dolomite is not active in steam reforming of methane, and therefore the lower heating value of the gas from the cracking of lower hydrocarbons does not drop significantly [9]. The efficiency of tar elimination reaches up to $99 \%$ [3, 9, depending on the operating conditions (retention time, temperature, and various other agents). The optimum temperature ranges from $800-900^{\circ} \mathrm{C}$, and the retention time ranges from $0.3-0.8$ seconds. Dolomite calcination is 


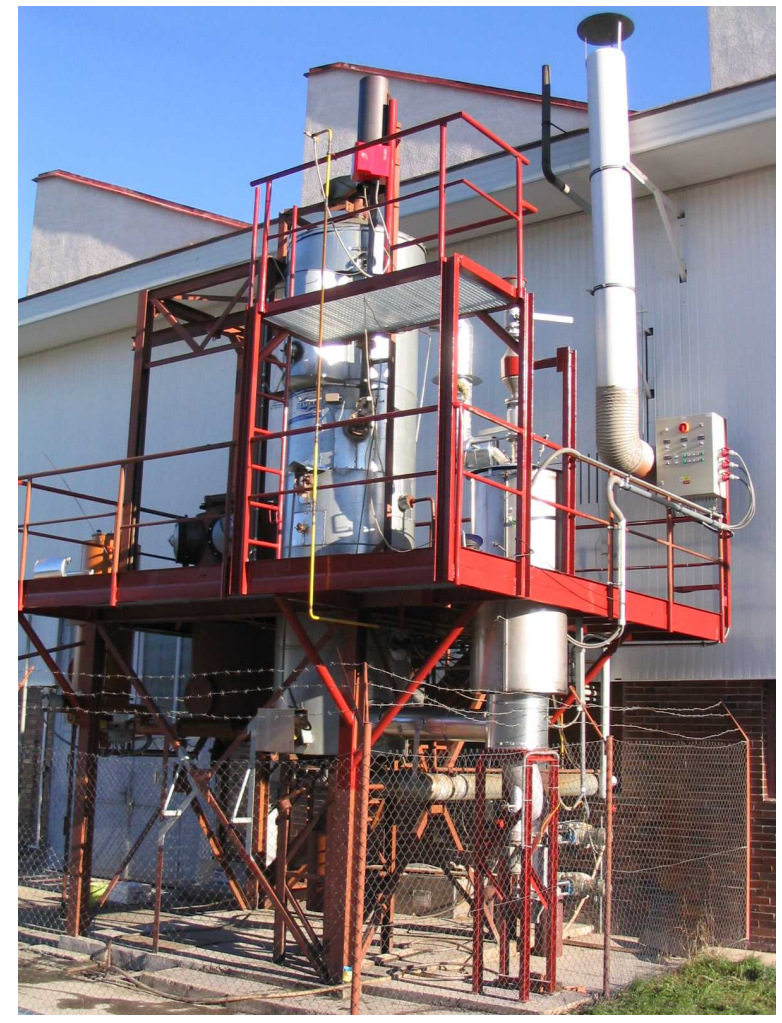

Figure 1. Atmospheric fluidized bed gasifier Biofluid.

extremely important for proper elimination of tar. If dolomite is calcinated, its activity rises tenfold [3].

\subsection{Calcination}

Dolomite calcination is a complex process, occurring in high temperatures, that transforms original material and comprises two distinct stages [14. The calcination process depends on several factors: temperature, grain size, dolomite composition, heating speed, and ambient conditions (partial pressure of $\mathrm{CO}_{2}$ ) [12, 15, 16]. Less stable $\mathrm{MgCO}_{3}$ is destructed in the presence of $\mathrm{CO}_{2}$ in temperatures exceeding $600{ }^{\circ} \mathrm{C}[15-17$. The reaction creates the so-called "half-calcinated" dolomite $\left(\mathrm{MgO} \cdot \mathrm{CaCO}_{3}\right)$ which is stable if the temperatures do not change and if the ambient partial pressure of $\mathrm{CO}_{2}$ is lower than the corresponding steady partial pressure of $\mathrm{CO}_{2}$. If the temperatures rise, calcination of $\mathrm{CaCO}_{3}$ occurs as well. An increase in $\mathrm{CO}_{2}$ results in a higher calcination temperature of $\mathrm{CaCO}_{3}$. The activity of calcinated dolomite depends on the size of the crystal particles and on the porousness of the stone, which is directly influenced by calcination. The so-called re-calcination, which is a reverse reaction of calcium oxide to carbonate accompanied by a temperature drop and/or by a rise in partial pressure of $\mathrm{CO}_{2}$, is another disadvantage of the technology [16].

\section{EXPERIMENTAL MEASURING IN Biofluid 100}

The research of gas cleaning at the Energy Institute of the Faculty of Mechanical Engineering in Brno has

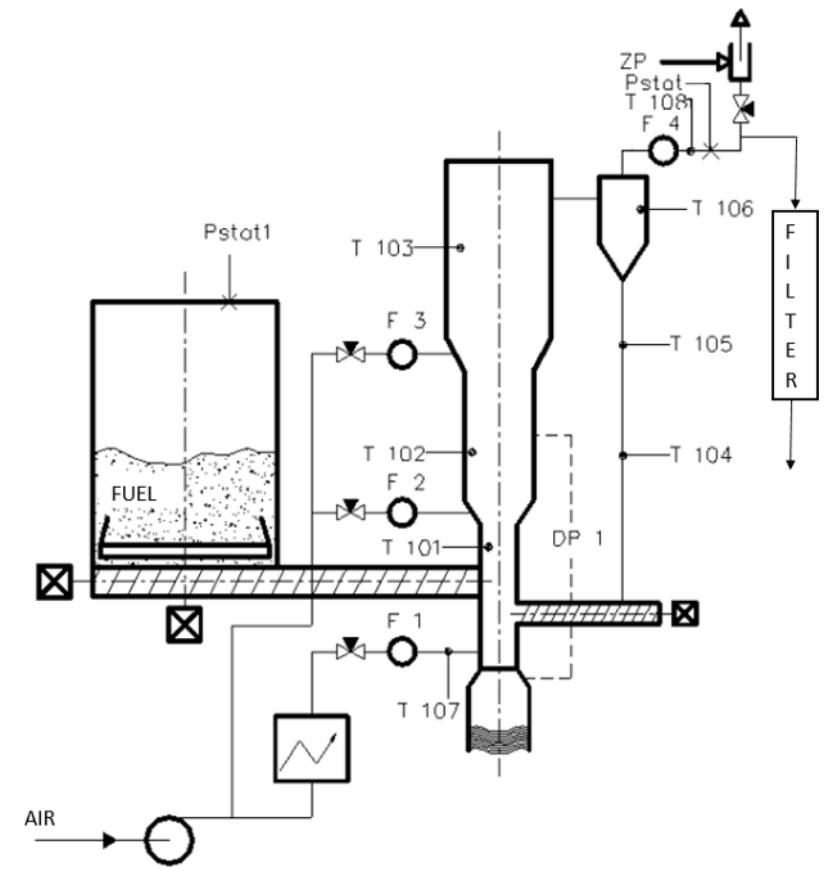

Figure 2. Simplified layout of the gasifier connections. Measured quantities: (T101-103) temperatures in the gasifier; (T104-105) temperatures under the cyclone; (T106) temperature inside the cyclone; (T107) temperature of the incoming primary air; (T108) gas temperature at jacket outlet; (F1-3) air flows; (F4) gas flow; (Pstat) outlet gas pressure; (Pstat1) tank pressure; (DP1) fluidized bed pressure difference.

focused on wet scrubbing technologies. Researchers have been successful in the use of water as a scrubbing fluid, and in the use of organic solvent (methyl ester of rapeseed oil). Both technologies present values below $50 \mathrm{mg} / \mathrm{m}_{\mathrm{n}}^{3}$ of tar in the gas. Research has slowly shifted to dry catalytic cracking, which may bring outstanding and more comprehensive solutions to gas cleaning. The objective here is to assemble a pilot verification route with a combustion engine.

The experiments were conducted in the atmospheric fluid gasifier Biofluid 100, which has been running since 2000 [18. The equipment has a stationary fluidized bed and may be operated in gasification and/or combustion mode.

Reactor specifications:

- power output (in produced gas) $100 \mathrm{~kW}_{\mathrm{t}}$;

- power input (in fuel) $150 \mathrm{~kW}_{\mathrm{t}}$;

- wood consumption max. $40 \mathrm{~kg} / \mathrm{h}$;

- air flow rate $\max .50 \mathrm{~m}_{\mathrm{n}}^{3} / \mathrm{h}$.

The fuel is supplied from a fuel storage tank which is equipped with a shovel, and it is fed into the reactor via screw conveyer with a frequency converter. Compressed air is lead into the reactor under the grate (primary air), the secondary and tertiary air is further supplied in two height levels. Wood pellets or highquality pure wood sawdust of $20-30 \%$ humidity are ideal fuels for fluid gasifier. Constant humidity [19], 


\begin{tabular}{cccccccccc}
\hline & $\mathrm{Na}_{2} \mathrm{O}$ & $\mathrm{K}_{2} \mathrm{O}$ & $\mathrm{MgO}$ & $\mathrm{CaO}$ & $\mathrm{SiO}_{2}$ & $\mathrm{Al}_{2} \mathrm{O}_{3}$ & $\mathrm{Fe}_{2} \mathrm{O}_{3}$ & $\mathrm{CO}_{2}$ & Others \\
\hline H. Lánov & 0 & 0.24 & 17.6 & 32.87 & 2.44 & 1.34 & 0.31 & 45.03 & 0.14 \\
\hline
\end{tabular}

TABLE 1. Chemical composition of dolomite [wt\%].

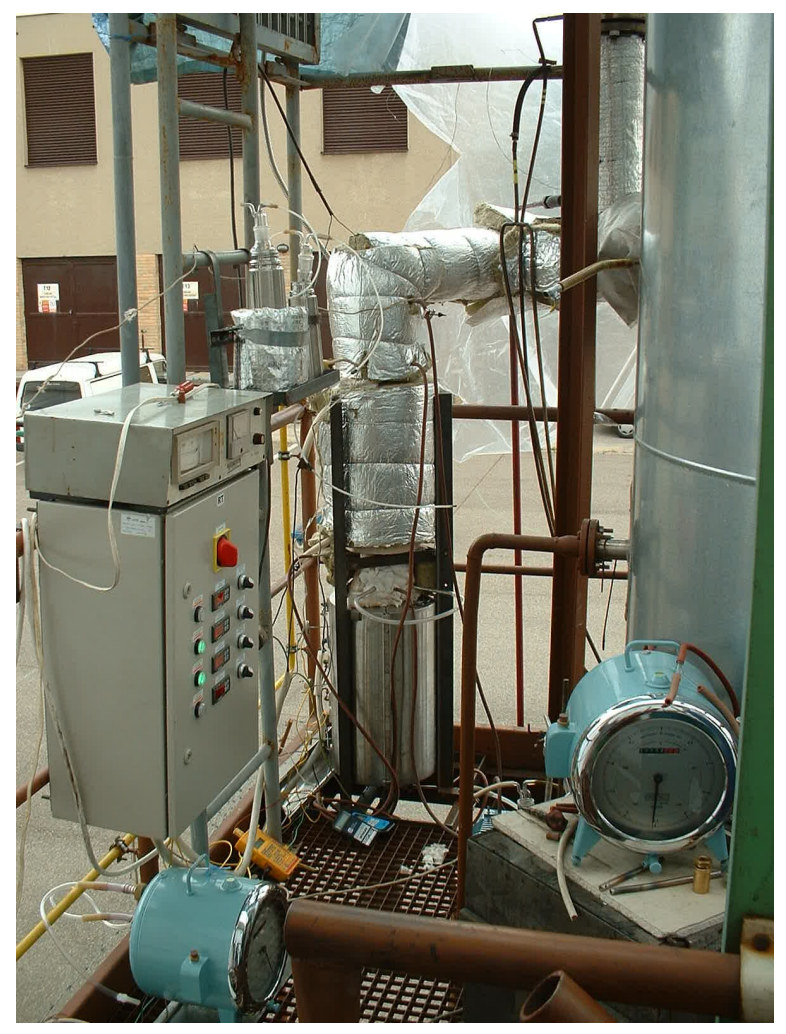

FiguRE 3. Laboratory verification route.

low ash content and the shape stability [20] of wood pellets are their huge assets. However, in order to imitate real operations as closely as possible, we used sawdust from spruce $(2-3 \mathrm{~cm})$ with $30 \%$ humidity.

\subsection{Methods OF MEASUREMENT ON EXPERIMENTAL UNIT BIOFLUID}

Gas quality measurements are usually carried out in two ways. One consists of an on-line monitoring of gas composition with simultaneous gas sampling into gastight glass sample containers. The samples are subsequently analysed using a gas chromatograph. The tar sampling is carried out in line with IEA methodology [21] by capturing tar in a solution that is subsequently analysed by gas chromatograph with a mass spectrometer. The presence of $\mathrm{HCl}, \mathrm{HF}$ and $\mathrm{NH}_{3}$ in the gas is examined by trapping them in an $\mathrm{NaOH}$ solution.

The operating parameters are monitored during operation and continuously recorded by the control computer. They include, in particular, the mass flow of fuel, the temperatures at various points of the unit, the pressure difference in the fluidized bed, the gas flow and pressure, and the temperature and flow of air.

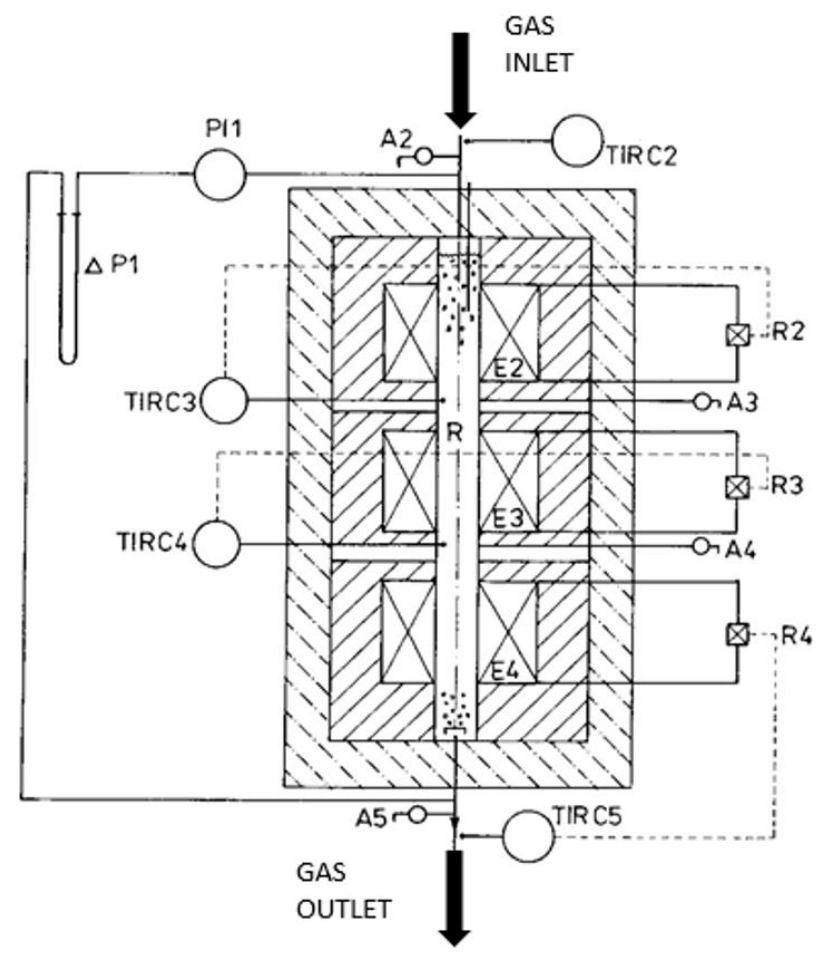

FiguRE 4. Diagram of a verification route. Measured quantities and scheme description: (TIR C2-5) temperatures; (PI1) inlet gas pressure; $(\Delta \mathrm{P} 1)$ gas pressure difference; (A2-5) sampling points; (R2-4) regulation of electric heating.

\section{VERIFICATION OF CONDITIONS OF CATALYTIC CRACKING ON STAND}

The verification of the dolomite ability to function as a catalyst in tar cracking, and the verification of the operating conditions were conducted in a stand with a 5 l.min-1 gas flow rate.

Dolomite was selected as a catalyst thanks to its availability, low purchase price and thanks to the fact that the first tar cracking occurs at a temperature of around $700^{\circ} \mathrm{C}$. The material grain was opted using a literary search and calculations obtained during the process of filter design. Dolomite from Horní Lánov was purchased for the verification (see Table 1). The grainy texture of the material used was about $1-1.5 \mathrm{~mm}$.

The measured gas was heated to $800-900^{\circ} \mathrm{C}$. The gas further entered a dolomite filter with electric heating, which regulates the temperature from 800 to $1200^{\circ} \mathrm{C}$. Prior to sampling, the dolomite was calcinated for $3-4$ hours at $950^{\circ} \mathrm{C}$, and it was continuously blown through with air. The filter design impedes continuous replacement of the catalyst; therefore new fillings of dolomite were used for every temperature, 


\begin{tabular}{|c|c|c|c|c|c|c|}
\hline \multirow[t]{2}{*}{ Temperature in reactor } & \multicolumn{2}{|c|}{$855^{\circ} \mathrm{C}$} & \multicolumn{2}{|c|}{$936^{\circ} \mathrm{C}$} & \multicolumn{2}{|c|}{$941^{\circ} \mathrm{C}$} \\
\hline & inlet & outlet & inlet & outlet & inlet & outlet \\
\hline$\Sigma \mathrm{BTX}\left[\mathrm{mg} / \mathrm{m}_{\mathrm{n}}^{3}\right]$ & 24425 & 4626 & 23305 & 72 & 15865 & 235 \\
\hline$\Sigma \operatorname{tar}\left[\mathrm{mg} / \mathrm{m}_{\mathrm{n}}^{3}\right]$ & 11625 & 623 & 10980 & 2 & 8185 & 35 \\
\hline Tar red. efficiency & \multicolumn{2}{|c|}{$94.64 \%$} & \multicolumn{2}{|c|}{$99.98 \%$} & \multicolumn{2}{|c|}{$99.57 \%$} \\
\hline $\mathrm{LHV}\left[\mathrm{MJ} / \mathrm{m}_{\mathrm{n}}^{3}\right]$ & 7.450 & 6.931 & 7.723 & 6.267 & 7.482 & 6.152 \\
\hline
\end{tabular}

TABLE 2. Reduction of tar in verification route.

\begin{tabular}{crrrrrrrr}
\hline Temperature in reactor & \multicolumn{2}{c}{$855^{\circ} \mathrm{C}$} & & \multicolumn{2}{c}{$936^{\circ} \mathrm{C}$} & & \multicolumn{2}{c}{$941{ }^{\circ} \mathrm{C}$} \\
\cline { 2 - 3 } & inlet & outlet & & inlet & outlet & & inlet & outlet \\
\hline $\mathrm{CO}_{2}$ & 15.28 & 17.66 & & 15.13 & 17.13 & & 15.35 & 18.56 \\
$\mathrm{H}_{2}$ & 13.98 & 15.44 & & 14.11 & 19.55 & & 13.95 & 19.14 \\
$\mathrm{CO}$ & 16.35 & 20.8 & & 16.53 & 20.31 & & 16.67 & 20.86 \\
$\mathrm{CH}_{4}$ & 2.99 & 2.73 & & 3.05 & 1.58 & & 2.93 & 1.05 \\
$\mathrm{~N}_{2}$ & 49.53 & 42.53 & & 49.41 & 41.35 & & 49.48 & 40.26 \\
$\mathrm{C}_{x} \mathrm{H}_{y}$ & 1.78 & 0.75 & & 1.72 & 0.01 & & 1.58 & 0.02 \\
\hline
\end{tabular}

TABLE 3. Gas composition [vol\%].

and max. 3-4 samples of tar and 4-5 samples of gas for each dolomite filling were taken.

Specifications of the verification equipment:

- diameter $3.0 \mathrm{~cm}$;

- height $0.3 \mathrm{~m}$;

- flow rate $5 \mathrm{l} / \mathrm{min}=8.3 \cdot 10^{-5} \mathrm{~m}_{\mathrm{n}}^{3} / \mathrm{h}$;

- gas temperature $800-900^{\circ} \mathrm{C}$;

- superficial velocity $\langle v\rangle=\frac{V_{p}}{S}=\frac{V_{p}}{\pi d^{2} / 4}=0.48 \mathrm{~m} / \mathrm{s}$, where $V_{p}$ is the flow rate of the gas through the filter $\left[\mathrm{m}_{\mathrm{n}}^{3} / \mathrm{h}\right]$ and $S$ is the cross section of the filter $\left[\mathrm{m}^{2}\right]$;

- retention time $\tau_{s}=\frac{\text { high }}{\langle v\rangle}=0.61 \mathrm{~s}$.

The results are shown in Table 2 and prove that if temperatures rise above $900{ }^{\circ} \mathrm{C}$, the amount of tar drops sufficiently, and the gas may be used in engines. Table 3 presents the changes in gas composition. The indicated temperature is an average value of TIR C2 and TIR C3. Samples of gas and tar were taken at the A5 sampling spot (see the diagram in Fig. 4).

Gas from the gasification of spruce wood scobs $(20 \%$ moisture content) was used in the experiments. The temperature in the gasifier reached $800-820^{\circ} \mathrm{C}$; the excess pressure compared to atmospheric pressure was about $400 \mathrm{~Pa}$, and the gasification ratio $e=0.35-0.4$; $35 \mathrm{~m}_{\mathrm{n}}^{3} / \mathrm{h}$ of produced gas.

\section{Results, evaluation And CONCLUSIONS}

We reached $99.5 \%$ efficiency in tar elimination, which corresponds with data published by some of the international authors 3, 22. Simell and his team conducted a series of studies using model compounds and tar substitutes to test the efficiency of dolomite and other carbonate rocks at $900-1000{ }^{\circ} \mathrm{C}$. The catalysts were calcinated at $900^{\circ} \mathrm{C}$ and operated at $900{ }^{\circ} \mathrm{C}$; tar elimination efficiency ranged from 86 to $99 \%$. Dolomite efficiency increased with a rising $\mathrm{Ca}: \mathrm{Mg}$ ratio and with a rising iron content in the gasified material [23, 24]. Delgado et al. obtained similar results [25]. Most of the results of tar elimination testing using natural catalysts published in research literature are based on laboratory applications and tested a model gas, not a real gas from biomass gasification.

Our results obtained on the gasification unit in realoperation conditions prove that dolomite catalysts are suitable for the cleaning of gas from biomass gasification, namely for elimination of tar from the gas. The purity of the gas reached 2 and $35 \mathrm{mg} / \mathrm{m}_{\mathrm{n}}^{3}$, which complies with the requirements on purity of the gas for use in cogeneration units (the maximum admissible gas content is commonly $50 \mathrm{mg} / \mathrm{m}_{\mathrm{n}}^{3}$ and/or zero tar condensate in the gas [26]). Our tar elimination method presents several advantages compared to other types of gas cleaning. Natural catalysts are cheap and are not subjected to so-called slow-degrading catalyst poisoning. They also eliminate sulphur and chlorine compounds. A proper equipment design allows for the implementing of a filter as a barrier separator of solids. Some of the disadvantages of natural catalysts include high operating temperatures and the fact that the relevant equipment must be operated together with a gas generator in order to minimize heat losses.

\section{ACKNOWLEDGEMENTS}

The presented results were obtained within the framework of the NETME CENTRE PLUS (LO1202) project, created with financial support from the Ministry of Education, Youth and Sports of the Czech Republic under the "National Sustainability Programme I". 


\section{REFERENCES}

[1] BTG - Biomass Technology Group; Tar \& Tar Removal, http://www.btgworld.com/technologies/ tar-removal.html\#tar, (5.11.2005).

[2] Bridgewater, A. V.: The Technical and Economic Feasibility of Biomass Gasification for Power Generation. Energy Research Group, Aston University, Birmingham, (1995) Fuel 74:5.

[3] Sutton D. et. al.: Review of literature on catalysts for biomass gasification, Fuel Processing Technology 73, 155-173, (2001). DOI:10.1016/S0378-3820(01)00208-9

[4] Lisý, M., Baláš, M., Moskalík, J., Štelcl, O. (2012). Biomass gasification - primary methods for eliminating tar. Acta Polytechnica, 52(3), 66-70.

[5] Baláš, M., Lisý, M., Štelcl, O. (2012). The effect of temperature on the gasification process. Acta Polytechnica, 52(4), 7-11.

[6] Milne T.A., Evans R.J, Abatzoglou N.: Biomass Gasifier „Tars": Their Nature, Formation and Conversion, NREL/TP-570-25357, USA, (1998).

[7] Skoblia, S: Modification of Gas Composition for Biomass Gasification, PhD Thessis. VŠCHT Praha, (srpen 2004).

[8] Simell, P.: Catalytic hot gas cleaning of gasification gas, VTT 1997, PhD thesis, (1997).

[9] Gusta E., Dalai A.K, Uddin M.A., Sasaoka E.: Catalytic Decomposition of Biomass Tars with Dolomite, Revised Manuscript, Energy \& Fuel, 27.3.2009. http://pubs.acs.org

[10] Myrén C., Hörnel Ch., Björnbom E., Sjöström K.: Catalytic tar decomposition of biomass pyrolitic gas with combination of dolomite and silica, Biomass and Bioenergy 23 ,217-227, (2003).

[11] Ordorica J.M.A., Cabanillas A.: Methods to Reduce Tars Production during the Gasification Proces, http://www .mam.gov.tr/bigpower/Workshop2/16.ppt 24.3.2009.

[12] McIntosh, R.M., Sharp, J.H., Wilburn, F.W.: The thermal decomposition of dolomite, Thermochimica Acta, 165, pp. 281-296, (1990). DOI:10.1016/0040-6031(90)80228-Q

[13] Corella J., Narvaéz I., Orío A.: Criteria for Selection of Dolomites and Catalysts for Tar Elimination from Biomass Gasification Gas; Kinetic Constants, New Catalysts for Clean Environment, the 2nd symposium of VTT Research Programme on Chemical Reaction Mechanisms, Espoo, (January 1996)

[14] Hehl, M., Helmrich, H., Schugerl, K.: Dolomite Decomposition in a High Temperature Fluidized Bed Reaktor., Chem. Technol. Biotechnol. 1983, 33A, 730-737.
[15] Hartman M., Trnka O., Veselý V., Svoboda K.: Predicting the rate of thermal decomposition of dolomite, Chemical Engineering Science, Vol. 51, No. 23, pp. 5229-5232, (1996). DOI:10.1016/S0009-2509(96)00363-6

[16] Wiedemann H.G., Bayer, G.: Note of the thermal decomposition of dolomite, Thermochimica Acta, 121, 479-485, (1987). DOI:10.1016/0040-6031(87)80195-8

[17] Boyton R.S.: Chemistry and Technology of Lime and Limestone, pp. 159-170, Willey, N.York, USA, (1980).

[18] Lisý, M., Baláš, M., Moskalík, J., \& Pospíšil, J. (2009). Research into biomass and waste gasification in atmospheric fluidized bed. Paper presented at the Proceedings of the 3rd WSEAS International Conference on Energy Planning, Energy Saving, Environmental Education, EPESE '09, Renewable Energy Sources, RES '09, Waste Management, WWAI '09, 363-368.

[19] Križan, P., Matúš, M., Beniak, J., Kováčová M.: "Stabilization Time as an Important Parameter After Densification of Solid Biofuels." Acta Polytechnica 54(1):35-41, (2014). DOI:10.14311/AP.2014.54.0052

[20] Menind, A., Križan, P., Šooš, L., Matúš, M., Kers, J.: Optimal conditions for valuation of wood waste by briquetting. Paper presented at the Proceedings of the International Conference of DAAAM Baltic "Industrial Engineering", 187-192, (2012).

[21] Van Paasen, S.V.B et al.: Guideline for Sampling and Analysis of Tar and Particles in Biomass Producer Gases. Final report documenting the guideline, R\&D work and dissemination 2002, ECN-C-02-090.

[22] Chłond, R., Najser, J.: Analysis of gas purification technology from biomass gasification based on work of ceramic filter. [Analiza technologii oczyszczania gazu z procesu zgazowania biomasy na przykładzie pracy filtru ceramicznego] Rynek Energii, 88(3), 107-112.

[23] Tuomi, S., Kurkela, E., Simell, P., Reinikainen, M. (2014). Behaviour of tars on the filter in high temperature filtration of biomass-based gasification gas. Fuel, 139, 220-231. DOI:10.1016/j.fuel.2014.08.051

[24] Simell P.A, Hakala N.A.K, Haario H.E., Krause, A.O.I.: Catalytic Decomposition of Gasification Gas Tar with Benzene as the Model Compound, Industrial \& Engineering Chemistry Research 199736 (1), 42-51. DOI:10.1021/ie960323x

[25] Delgado J., Aznar M.P, Corella J.: Biomass Gasification with Steam in Fluidized Bed: Effectiveness of $\mathrm{CaO}, \mathrm{MgO}$, and $\mathrm{CaO}-\mathrm{MgO}$ for Hot Raw Gas Cleaning, Industrial \& Engineering Chemistry Research 199736 (5), 1535-1543. DOI:10.1021/ie960273w

[26] Najser, J., Ochodek, T., Chłond, R.: Functioning of installation for a biomass gasification and economic aspects of electricity generation. [Charakter pracyinstalacji słu zaçej do zgazowania biomasy a aspekty ekonomiczne procesu generacji energii elektrycznej] Rynek Energii, 85(6), 68-74, (2009). 